\title{
ROLE OF PROTECTED AMINO ACIDS IN RUMINANT'S PHYSIOLOGY: A REVIEW
}

\author{
HIYAM N. MATY \\ Department of Physiology, Biochemistry and Pharmacology, College of Veterinary Medicine, \\ University of Mosul, Iraq.
}

Received: 26 July 2020; Accepted: 31 August 2020

\begin{abstract}
This review was designed to shed light on the applications of rumen-protected amino acids (AA) and choline, undertaken by supplying ruminant's diet with rumen protected bypass products, and their effects on physiological aspects. AA and choline in a hydrogenated palmitic acid matrix, which provides optimum protection, undergo bypass to the rumen compartments, thereby avoiding the physical degradation in this part. Thus, AA and choline involves maximum release, high bioavailability and better absorption rate within alimentary tract. The balancing of ration formula with methionine, lysine, histidine, tryptophan and choline using a rumen protected form, may help to enhance production and permit for better flexibility during diet formulation. Rumen-protected AA and choline result in the most costeffective solution when formulating dairy diets based balance. Supplementation of rumen protected essential AA and choline is performed to maintain a healthy status, high bioavailable source of these substances, and improve the efficiency of protein metabolism. To sum up, dietary supplementation of rumen protected AA and choline enhances their availability in the gastrointestinal tract and production, with a significant improvement of body conditions, compared to unprotected form. Therefore we recommend using this protected AA and choline continuously in diet formula of ruminants.
\end{abstract}

Key words: Rumen protected methionine, rumen protected lysine, rumen protected tryptophan, rumen protected choline, ruminants

\section{INTRODUCTION}

Amino acids (AA) are the building units of proteins, which represent main constituents of animal tissues. AA plays a major role in various important metabolic and biochemical activities in the living cells, in addition to their role in growth and reproduction (Wu, 2014). The availability of

Corresponding author: Hiyam N. Maty

E-mail address: hemyatem@yahoo.com

Present address: Department of Physiology,

Biochemistry and Pharmacology, College of Veterinary Medicine, University of Mosul, Iraq.
AA and choline in food is crucial. It is important that ruminants consume sufficient amounts of AA to maintain their productivity and healthy status, thus the animals require a source of $\mathrm{AA}$ in the feed ingredients (Kung and Rode, 1996). Animals need both essential and non-essential AA with appropriate amounts for metabolic processes, whether to produce milk, build muscles or reproduction. The requirement of animals to specific AA and choline differs depending on the species, gender, diet and age, for instance, lysine (Lys) and methionine (Met) are standard first-limiting AA for dairy cows (Tedeschi et al., 2015). 
Many problems related to deficient AA and choline in the diet of farm animals are expected when these substances are not provided in sufficient amounts, thus the animals body cannot supply adequate proteins to maintain numerous metabolic functions and growth (figure 1) (Wu, 2014). As a result of destruction of available uncoated AA and choline in diet by rumen microflora, the dietary supplementation of rumen protected AA and choline is suggested to improve physiological functions, production and reproduction of animals (Ratika et al., 2018). Therefore, this study aimed to explain the Rumen-protected technology application on ruminants physiology and effects of supplementation of protected AA and choline when they bypass small intestine without degradation in rumen.

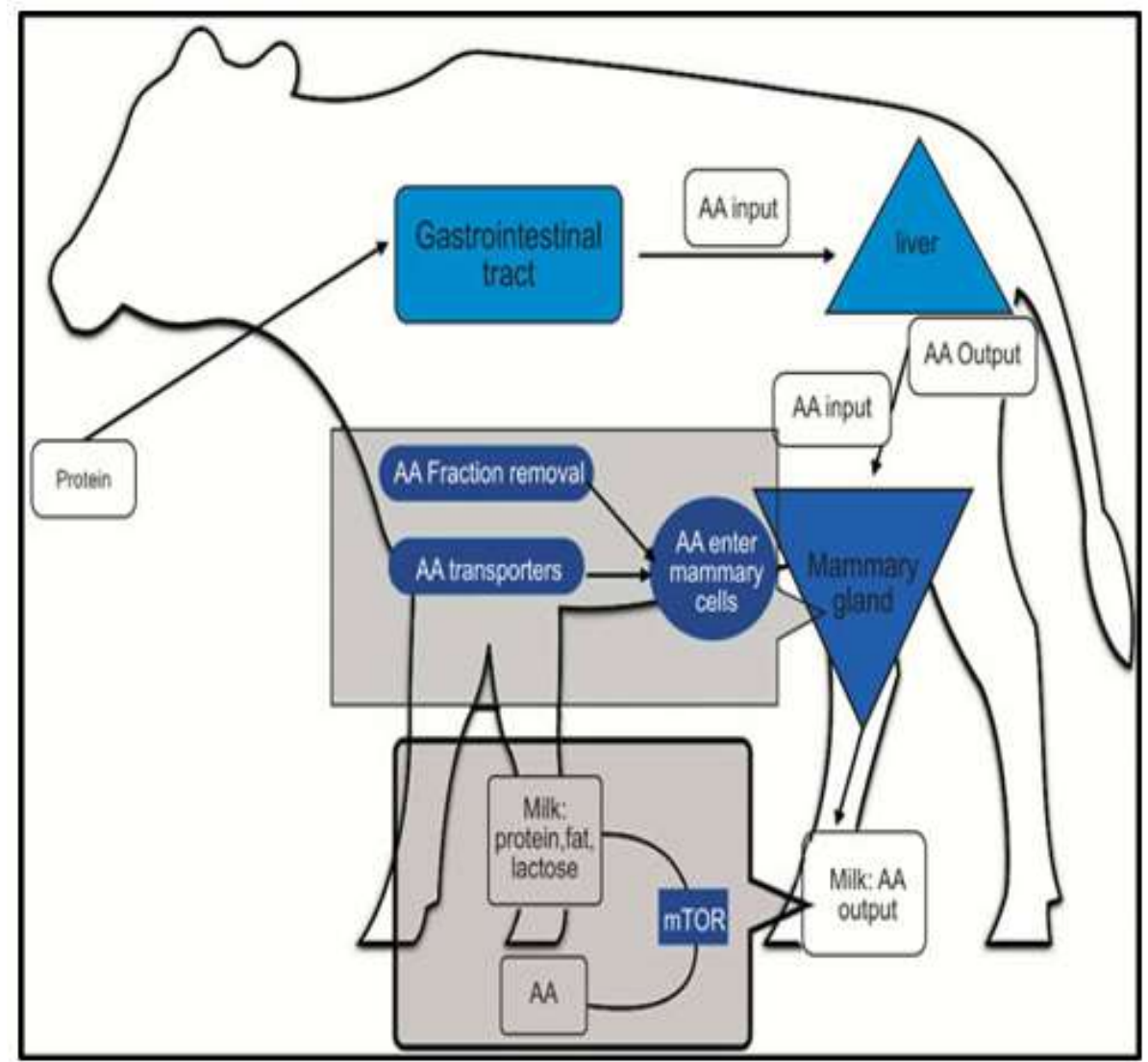

Figure 1: fate of dietary Crude Protein in ruminants (Wang et al., 2019)

\section{Rumen-protected AA technology (microencapsulation technology)}

In order to prevent a deficiency of AA and choline in ruminant diets they can obtain it from dietary manipulations, and adaptation the coating forms in adequate quantities of the various balanced diets (Ben Salem, 2010). The major challenge of AA and choline supplementation to ruminants as a complementary feed is the rumen: by the presence of normal flora that ferment any unprotected feed, these substances will be degraded by the enzymes produce by rumen microflora (Matthews et al., 2019). The microencapsulation technique includes using the ingredients (AA) or choline with spray freeze coat of a specific layer of hydrogenated palmitic fatty acid matrix to make it able to bypass the rumen and resists to physical damage that occurs in the rumen. Thus, the hydrophobic layer of this fatty acid prevents the protected AA and choline form microbial damaging in the rumen, giving the maximum digestibility and efficient absorption within the intestine, after they release in the lumen of gastrointestinal tract (A.O.A.C., 2005) (figure 2). 


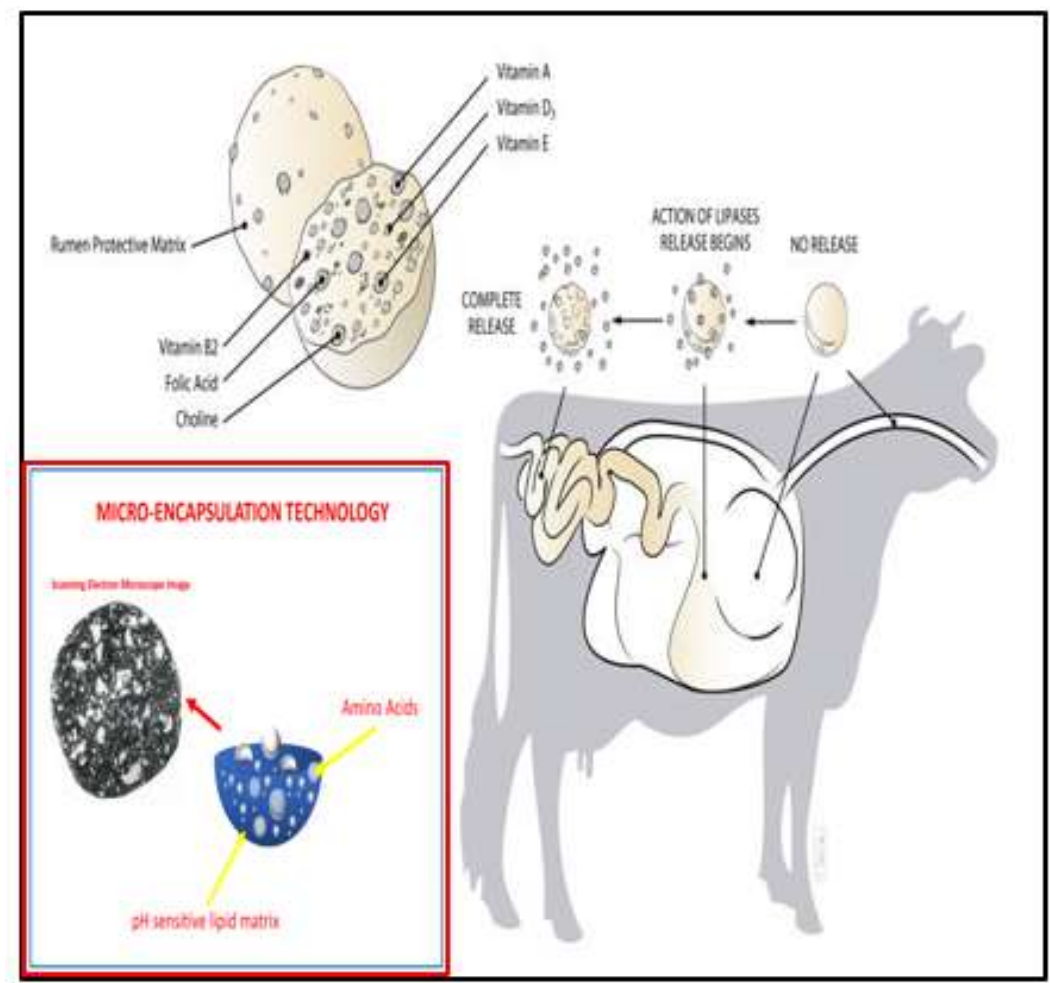

Figure 2: Microencapsulation technology of protected AA, choline and vitamins with a lipid matrix

\section{Methionine (Met)}

Met is a sulphur-containing AA which is a constituent of most proteins. It is one of the essential AA in the diet of vertebrates, and considered as the substrate for cysteine and taurine. The sulfur group is a distinctive characteristic of this $\mathrm{AA}$, and because it contains sulfur, it acts as a source of all AAs specially those containing sulfur. Met plays a crucial function in the building of proteins to the body. The sulfur atoms contribute to formation of cysteine and the biosynthesis of glutathione, thus Met acts as an antioxidant. In the liver, Met is adenylated and then converted into S-adenosyl Met (SAM). SAM is then converted to s-adenosyl homocysteine $(\mathrm{SAH})$ and with the presence of B6, the SAH is converted to cystathionine and then cysteine (Yin et al., 2019). Indeed, Met is also one of the limiting AA that is required for dairy ruminants to produce milk due to it involves in transmethylation reactions and synthesis of milk protein (Girard et al., 2010).

\section{Protected methionine}

Extensive investigations during last few years showed that diet supplements with encapsulated form of Met lead to improve milk content by increasing milk protein and fat. Exactly calculating AAs content in feed permits nutritionists to optimize the entire protein composition in diet. Tetsuo et al. (2019) proved that feeding dairy cattle with a diet rich with crude protein did not influence milk production compared to a diet rich with rumen-protected methionine (RPMet). The reason of improving milk production more than crude protein is that RPMet acts to reduce nitrogen excretion and improves nitrogen utilization (Panel et al., 2011). In addition, increase in milk production when supplement provided with RPMet through increasing dry matter intake (DMI) that enhances liver function (Batistel et al., 2017). It was noted that there is a close hormonal relationship between MET and prolactin hormone PRL, that is associated with milk production, it was found that milk production is induced by the increasing the prolactin receptors expression within the substantia nigra and hypothalamus of the elderly animals after 30 
days of treating with S-adenosyl-L - Met. Furthermore, the addition of the Met showed an increase in the number of receptors in the hypothalamus membranes (Muccioli and Di Carlo, 1989). Also, Supplementation with rumen protected Met plus lys will improve the daily gain in calves (Sai et al., 2014).

Met is an important AA that affects animal fertility, and it is known that the lack of Met in nutritional formula leads to a lack of fertility and even may affect fetal development during pregnancy or loss of pregnancy (abortion) because many of the AA are condensed in the ovary, uterus and in the fluid that surrounds the fetus (Lucy et al., 2014). Peñagaricano et al. (2013) proved in recent study dramatic changes in gene expression of ruminant embryos when they fed on RPM during lactation. Supplementation of RPM would improve embryonic growth by measuring Pregnancyspecific protein B (PSPB) level and is expanding the size of embryonic and amniotic vesicles, thus elevate the pregnancy rate with declination of abortion rate (Toledo et al., 2017).

Met and choline each have been the focus of a number of transition cow studies over the past 10-15 years. Interestingly, these two AA are metabolically related due to the fact that both compounds can serve as methyl donors, that is important in many biological activities in cells is that dependent on the methyl groups. This relationship between Met and choline is well studied in nonruminants however, in ruminants, especially dairy cows fed more on these two components as well as there is a insufficient evidence that Met can significantly alternative for choline (Pinotti et al ., 2005); quite, each of these AA has distinct effects on the transition cows (figure 3 ). In the preruminant lambs are getting abundance of choline from the milk, but in grown ruminants only minor amounts of methyl group nutrients are existing from the diet and Met synthase responsible for production of Met methyl groups from one-carbon pieces provided by tetrahydrofolate (choline) (Girard et al., 2010).

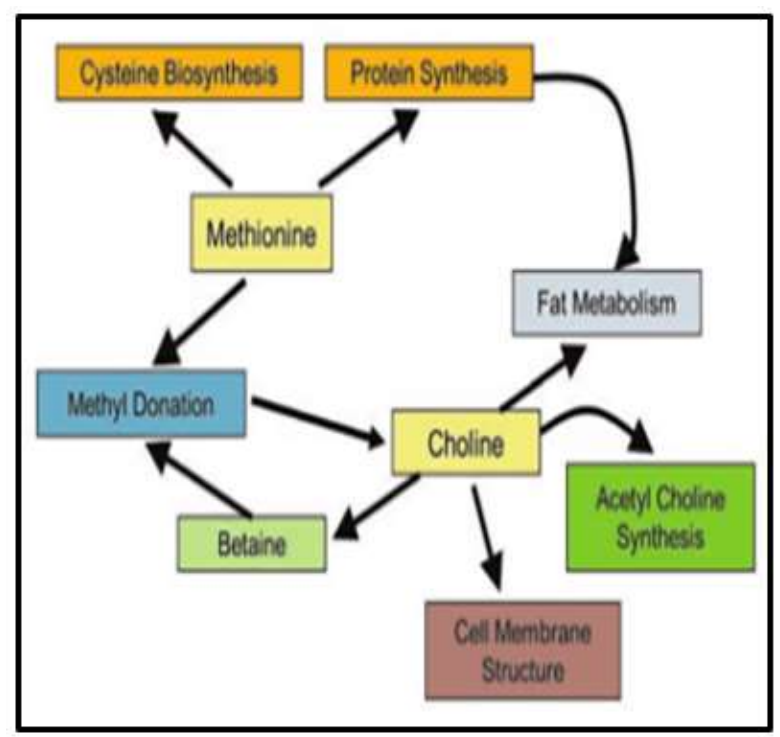

Figure 3: Correlation and metabolic functions of choline and Met

Interestingly, there is an improvement of immune function of the cows that fed on rumen-protected Met because, as they showed greater phagocytic function of the neutrophils harvested at 21 days postpartum (Osorio et al., 2013). In addition, Met acts to support animal performance by methyl donation for choline production, and choline supplementation promotes to extra betaine metabolite for the creation of sulfurcontaining AA (figure 4) (Ardalan et al., 2011). 


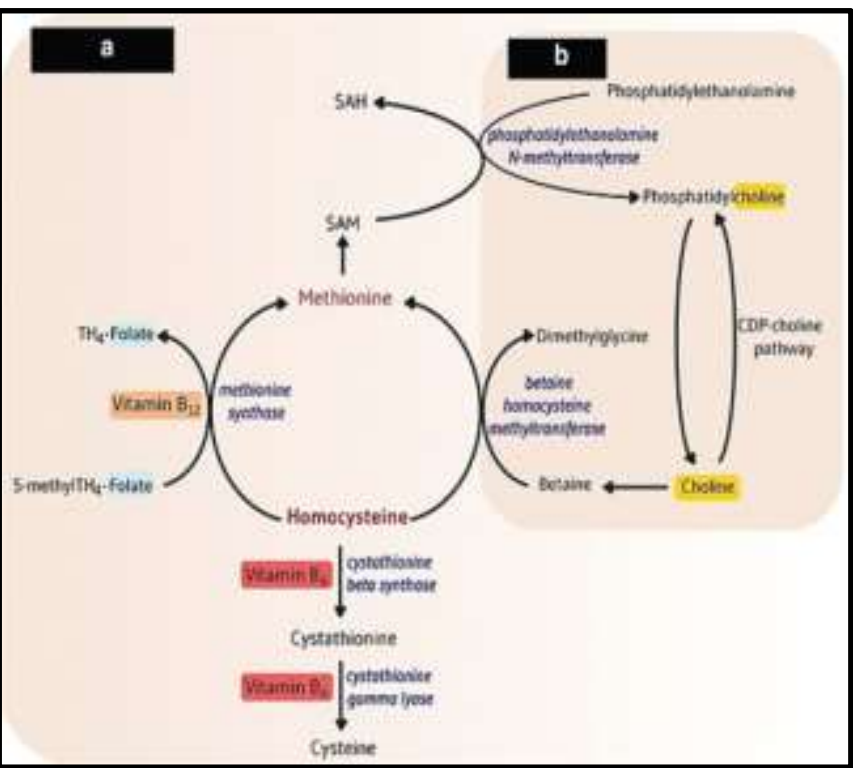

Figure 4: Path of homocysteine and formation essential AA (Abbasi et al., 2017)

In another study and During the transition phase (negative energy balance in dairy cattle), fed animals on RPC and RPMet showed an elevation of vitamin E level in plasma associated with increasing of total antioxidant capacity while malondialdehyde values may decrease (Sun et al., 2016).

\section{Lysine (Lys)}

Lys is an essential AA that must be existing in the feed. Lys is crucial for the creation of entire proteins, and is involved for the conservation of the proteins structure such as collagen and elastin, which construct all connective tissues such as skin, tendons, and bones. Lys is also a precursor to carnitine that required for lipids metabolism and energy. Furthermore lys may improve the immune system and perform cardiovascular system. Lys is one of those AA that the body is unable to synthesize it therefore; it must be obtained from dietary sources. Supplementation of lys acts to improves physiological functions such as protective effects from hypertension by preventing precipitation of lipoprotein-(a) to the arterial walls (Vuvor et al., 2017). Lys promotes the protein synthesis and increases milk production by increasing the viability of the epithelium tissue in the udder, whereas protein degradation was inhibit with in these cells, for this reason, lys is crucial in cattle diet for milk production (Lin et al., 2018).
Lys was first isolated from casein protein in milk; because $\beta$-Casein is one of the important milk proteins with high nutritional value, lys additive with other AA such as Met to the diet of early lactating cows will significantly increase $\beta$-casein expression in the bovine mammary epithelial cells via stimulation of the rapamycin complex 1 signaling pathway (Gao et al., 2015).

L-Lys is an essential AA that is available as a supplement for animal feed. Therefore, LLys is synthesized to increase growth of Corynebacterium glutamicum, the highly important charachter for its ability to produce L-glutamate and L-lys, which are required in animal diet, also it build up for the creation of almost entirely the L-amino acids with commercial form such as Lisoleucine, L-valine, L-threonine and Lserine (Junior et al., 2016).

\section{Protected lysine}

To improve the dairy cow production, rumen-protected lysine (RPL) is supplemented in a protected form due to its sensitivity to the acidic environment of the first part of the digestive tract; hence, coated lys will be effectively absorbed in the small intestine, yield positive effect on milk production (Lee et al., 2015). 
Lys and Met can synthesize L-carnitine in the mitochondria, cytosol, and lysosome by several-steps; firstly lys is methylated to form $\varepsilon$-N-trimethyl lys by methyltransferase, derived from Met, secondly, it released carnitine. L-carnitine is synthesized in the liver and transported by the bloodstream to cardiac and skeletal muscles, which play a role in fatty acid oxidation. The rate of Lcarnitine biosynthesis depends on lys in the supplemented diet, which may increase endogenous L-carnitine synthesis (Rebouche, 2014). Since carnitine is essential for mitochondrial fatty acids oxidation, this allows adequate energy supplies from fat by fat break down in the cell and observe energy from fat reserves, however the disorders of carnitine biosynthesis occur when inadequate lys in the diet or inability to bypass rumen. This may lead to insufficient energy supply and raises the possibility of brain and liver dysfunction (Longo et al., 2016). In addition, the added lys may have a significant immunological role by increasing serum zinc level, CD4 receptors, thus both zinc and lys act to activate thymulin to improve the process of differentiation and maturation of T- lymphocytes (Sugeng et al., 2015). Researchers improved Infusion mixture of the complete AA resulted in an increase in the plasma concentrations of several essential AA, glucagon and decreased growth hormone and depressed dry matter intakes (Weekes et al., 2006). In addition, the supplementation of both rumen-protected Met and rumen-protected lys enhance weight gain of growing calves and improve the efficiency of feed utilization, with an increase in the digestibility of nutrients, which leads to decrease costs (Gavade et al., 2019). Also, diet containing protected lys causes elevation of milk production in lactating cows (Liu et al., 2016).

\section{Histidine (His)}

Structurally, containing dipeptides (carnosine, anserine and balenine) has numerous therapeutic properties, physicochemical. Histidine acts as buffering system inside cells (homeostasis of acidbase), and regulates calcium. Physiologically, hisistidine is strongly dependent on non-oxidative forms of energy production fuelled to their skeletal muscles, and it is considered as a precursor of histamine in addition to the vital role in inflammatory agents and immune response (Dolan et al., 2019; Andersen et al., 2015).

\section{Protected histidine}

The researchers reported that deficiency in digested His in the feed causes decrease in the concentration of hemoglobin in cows. Also, an additional confirmation showed that low dietary his impair milk production and milk protein in dairy cows, but feeding on diets rich in rumen-protected histidine (RPHis) has the potential to reverse these effects. (Giallongo et al., 2016; Giallongo et al., 2017). Therefore, supplementation of diet with RP-His increases linearly with milk yield and milk protein synthesis. This may suggest that plasma his has exceeded the requirement with extra nitrogen converted to urea in the liver. Also, the dipeptides (carnosine, and anserine) of RP-His caused increased concentrations of AA in the muscle (Zang et al., 2019). Animals treated with rumen-protected His will affect positively on quality products of beef cattle (Sandberg et al., 2017).

\section{Tryptophan (Trp)}

There are two types of this AA: L and Dtryptophan and the difference between them are the direction of the molecule. Trp is an essential AA, which is used as building units for many proteins. It is considered as a precursor to the serotonin (acts as a neurotransmitter, melatonin and Niacin (vitamin B3). Also, trp plays vital roles in cytoskeleton in addition to the action by anchoring membrane proteins within the cell membrane (Slominski et al., 2002). The physiological effect of trp is same to the therapeutic effects of the melatonin, because it stimulates the secretion of melatonin from the pineal gland, and because the melatonin 
has indirect effects of gonadal function by its influence on gonadotropin-releasing hormone and then for the reproduction of the animals (Sánchez et al., 2008).

\section{Protected tryptophan}

It is reported that L-trp considered as an important AA in lambs and cattle. Thus, supplementation of Trp in a rumen protected form has beneficial influences on growth performance and health of beef cattle (Lee $e t$ al., 2019). Researchers mentioned that intravenous administration of L-trp leads to enhance in the secretion of gastrointestinal hormones and results in good meat quality in ruminants, but supplementation of encapsulated L-trp to safely passing from the rumen to intestine gives more desirable effects on the secretion of gastrointestinal hormones to give high absorption rate inside the intestinal cells (Lee et al., 2019).The gastrointestinal hormones that increased after oral administration of RPL-trp are cholecystokinin and pancreatic $\alpha$-amylase, which leads to an increase in the activity of the hormones in the duodenal fluids, as well as increasing the digestion rate of starch in the small intestine, Which is useful for increasing muscle mass and, hence body weight (Lee et al., 2020). The influence of dietary supplementation of RPL-trp was also observed on livestock during exposure to cold weather as a stress factor, when RPTrp enhances growth performance keeping the homeostasis and immune responses in beef steers in cool circumstances by elevating glucose level and reducing adipogenic gene expression (Lee et al., 2019).

\section{Choline}

Choline was firstly discovered at 1849 by German chemist named Adolph Strecker. After that in 1867 Bayer described the chemical construction of choline (McDowell, 1989). It can be found freely in the biological tissues. Choline is a quaternary ammonium base (trimethylamine 2-hydroxyethyl) $\quad\left[\left(\mathrm{CH}_{3}\right) 3 \mathrm{~N}+\mathrm{CH}_{2} \mathrm{CH}_{2} \mathrm{OH}\right]$, also called as trimethyl ethanolamine and it is considered as a nutrient with an amino acid-like metabolism. It is a vitamin-like substance (In the past, choline was classified as a vitamin B; however, because it is not directly involved in enzyme systems, it has since been described as a quasi-vitamin. Choline acts as an essential nutrient for mammals when an insufficient supplementation of Met and folate in the diet. Vitamin B12 is also involved in this process. The dynamic interactions among Met, vitamin B12, and folic acid introduced the conception of choline as a vitamin-like structure. Choline has two functional properties; the first, as a methyl donor, when it is considered as a source of biological synthesis of methyl and its compounds. Secondly, it involves lipids metabolism, such as the transport of fats, as a fatenhancing agent. Based on these functions, choline is a major source for energy and protein metabolism in mammals (Sathiyabarathi et al., 2016).

\section{Protected choline}

Although choline is not AA but extensively provide in protected from like fed supplement due to their crucial role in many metabolic and physiological functions. In the rumen choline is breakdown by a large number of microbes, Therefore, the availability of choline is decreased and then not enough to absorb. To bypass this step the choline is available in protected from by coating it with a layer of fatty acids to avoid destruction by the enzymes of rumen microbes (Ardalan et al., 2010; Pawar et al., 2015). After choline reaches the small intestine and because it has a positively charged molecule thereby not freely cross the plasma membrane of enterocytes, so will need carrier; and then for absorption, choline must be hydrolyzed by phospholipases in the intestine, after the fatty acids are broken down by the digestive enzymes, thereby making the choline free and easily absorbable in beneficial from (Blanco and Blanco, 2017).

Choline is necessary for synthesis of the neurotransmitter, acetylcholine, in addition, 
it acts as a source for acetylcholine after being transported in the neural cells, by carrier proteins, where it will eventually combine with acetyl CoA in the form the neurotransmitter acetylcholine (Wessler and Kirkpatrick, 2008).

The acetylated volatile fatty acids (VFA) increase when the protected choline is given and with it, the ability to digest increases with increasing $\mathrm{pH}$ in rumen. In addition, organic materials, raw protein, raw fibers, ether extract and nitrogen-free extract increased significantly in rumen (Mohsen et al., 2011). The Rumen protected choline RPC supplementation also reduces the exposure to hepatic fatty infiltration, thereby preventing fat accumulation in the liver and avoiding fatty liver syndrome, that usually occurs in animals after birth as a result of an increase in the requirement for energy due to an elevation of fatty acids transportation to mammary gland (Zom et al., 2011). Furthermore the RPC works to reduce the incidence of clinical ketosis (Ensink and Kampf, 2013).

In lactating animals, RPC supplementation increases milk production, firstly by increasing the digestibility and total VFA concentration, and decreasing ammonium. Secondly, by increasing the intestinal supply of choline, which improves the milk production by approximately $7 \%$ compared to controls (Leiva et al., 2015). There is evidence that casein increases in milk after giving RPC, and in this way choline works to increase the milk protein, fats and lactose. Thus, protected choline positively affects milk components (Grummer, 2011). Hence, the protected choline has positive effects on lactation particularly once feeding is began previous to calving and continues at the beginning of lactation (Grummer, 2011). When the body is exposed to negative energy balance, supplementation of protected choline to diet is essential to provide energy through export the triglycerides (TG) from the liver. Therefore RPC reduces TAG in the liver of dairy cows, thus increases milk yield and enriches it with fats (Arash et al., 2016). Choline acts as a major lipotropic factor in ruminants during lactation because it diminishes the extreme fat deposit in liver cells, with detectable buildup in milk production and its constituents (fat, lactose, total solids and protein) (Leiva et al., 2015).

\section{CONCLUSIONS}

Dietary supplementation of rumen protected AA can promote production and reproduction performance in cattle and sheep. However, many researchers proposed that increasing total AA availability in the small intestine leads to a desirable effect via enhancing a variety body functions.

\section{REFERENCES}

A.O.A.C. (2005): Association of Analytical Chemists, Official Method of Analysis 18th Ed collegiate press, Washington, D. C., U. S. A.

Abbasi, IHR.; Abbasi, F.; Soomro, RN.; Abd El-Hack, ME.; Abdel-Latif, MA.; Li, W.; Hao, R.; Sun, F.; Bodinga, BM.; Hayat, K.; Yao, J.; Cao, Y.(2017): Considering Choline as Methionine Precursor, Lipoproteins Transporter, Hepatic Promoter and Antioxidant Agent in Dairy Cows. AMB Express. 7(1):214.

Andersen, Hjalte, H.; Jesper, E.; ArendtNielsen, L. (2015): "Human surrogate models of histaminergic and nonhistaminergic itch" (PDF). Acta Dermato-Venereologica. 95 (7): 771777.

Arash, S.; D'Occhio, MJ.; Al Jassim, R. (2016): The role of rumen-protected choline in hepatic function and performance of transition dairy cows. British Journal of Nutrition. 116, 3544.

Ardalan, M.; Dehghan, BM.; Rezayazdi, K.; Hossein, ZN. (2011): The effect of rumen-protected methionine and choline on plasma metabolites of 
Holstein dairy cows. J Agric Sci. 2011; 149:639-646.

Ardalan, M.; Rezayazdi, K.; Banadaky, MD. (2010): Investigation on the effect of supplementing rumen protected forms of methionine and choline on health situation and reproductive performance of Holstein dairy cows. Pak. J. Biol. Sci. 12(1):69-73.

Batistel, F.; Arroyo, JM.; Bellingeri, A.; Wang, L.; Saremi, B.; Parys, C.; Loor, J.J. (2017): Ethyl-cellulose rumenprotected methionine enhances performance during the periparturient period and early lactation in Holstein dairy cows. Journal of Dairy Science. 100, 7455-7467.

Ben Salem, H. (2010): Nutritional management to improve sheep and goat performances in semiarid regions. R. Bras. Zootec, 39: 337-347.

Blanco, A.; Blanco G. (2017): Medical Biochemist. Chapter 27 Vitamins. Copyright (C) 2017 Elsevier Inc. All rights reserved.

Dolan, E.; Saunders, BR.; Harris, RC.; Pereira, JE.; Bicudo, W.; Bishop, DJ.; Sale, C.; Gualano, B.(2019): Comparative physiology investigations support a role for histidine-containing dipeptides in intracellular acid-base regulation of skeletal muscle. Comparative Biochemistry and Physiology Part A: Molecular \& Integrative Physiology. 234: 77-86.

Ensink, J.; Kampf, D. (2013): Effect of rumen protected choline chloride in dairy cows. Freising: Jahrestagung der Bayrischen Arbeitsgeminschaft Tierenahrung . pp. 77-80.

Gao, HN.; Zhao, SG.; Zheng, N.; Zhang, YD.; Wang, SS.; Zhou, XQ.; Wang, JQ.(2015): Combination of Histidine, Lysine, Methionine, and Leucine Promotes $\beta$-casein Synthesis via the Mechanistic Target of Rapamycin Signaling Pathway in Bovine Mammary Epithelial Cells. J Dairy Sci. Sep; 100(9): 7696-7709.
Gavade, VS.; Gadegaonkar, GM.; Ramteke, BN.; Pagdhune, AG.; Kanduri, AB.(2019): Effect of Supplementation of Rumen Protected Methionine and Lysine in Crossbred Calves.. International Journal of Livestock Research 9, 4.

Giallongo, F.; Harper, MT.; Oh, J.; Parys, C.; Shinzato, I.; Hristov, AN.(2017): Histidine deficiency has a negative effect on lactational performance of dairy cows. J. Dairy Sci. 2017; 100:2784-2800.

Giallongo, F.; Harper, MT.; Oh, J.; Lopes, JC.; Lapierre, H.; Patton, RA.; Parys, C.; Shinzato, I.; Hristov, AN.(2016): Effects of rumen-protected methionine, lysine, and histidine on lactation performance of dairy cows. J. Dairy Sci. 99:4437-4452.

Girard, CL.; Preynat, A.; Graulet, B.; Lapierre, H. (2010): Could 'minor' nutrients such as B vitamins alter major metabolic pathways in lactating dairy cows?, In: Energy and protein metabolism and nutrition, G.M. Crovetto (Ed.), pp. 235-243. Wageningen Academic Publishers Wageningen. The Netherlands.

Grummer, RR. (2011): Managing the Transition Cow-Emphasis on Ketosis and Fatty Liver Syndrome: Available from

http://www.vtdairy.dasc.vt.edu/pdf/co w_college/2011/18\%20grummerpaper.pdf)

Junior, L.; Alberto, L.; Letti, GV.; Soccol, CR.; Junior, L.; Alberto, L.; Letti, GV.; Soccol, CR. (2016): Development of an L-Lysine Enriched Bran for Animal Nutrition via Submerged Fermentation by Corynebacterium glutamicum using Agroindustrial Substrates. Brazilian Archives of Biology and Technology. 59.

Kung, L.; Rode, LM. (1996): AA metabolism in ruminants. Animal Feed Science and Technology. 59: 1-3: 167172. 
Lee, C.; Giallongo, F.; Hristov, AN.; Lapierre, H.; Cassidy, TW.; Heyler, KS.; Varga, GA.; Parys, C.(2015): Effect of dietary protein level and rumen-protected AA supplementation on AA utilization for milk protein in lactating dairy cows. J. Dairy Sci. 98:1885-1902.

Lee, S.; Lee, K.; Wang, T.; Lee, J.; Jung, U.; Nejad, JG.; Oh, Y.; Baek, Y.; Kim, K.; Lee, H. (2019): Intravenous administration of L-tryptophan stimulates gastrointestinal hormones and melatonin secretions: study on beef cattle. J Anim Sci Technol. 61(4): 239-244.

Lee, S.; Lee, K.; Wang, T.; Lee, J.; Jung, U.; Nejad, JG.; Oh, Y.; Baek, Y.; Kim, K.; Hong-Gu, L. (2020): Administration of encapsulated L-tryptophan improves duodenal starch digestion and increases gastrointestinal hormones secretions in beef cattle. AsianAustralas J Anim Sci. 33. 1:91-99.

Leiva, T.; Cooke, R.; Brandao, A. (2015): Effects of rumen protected choline supplementation on metabolic and performance responses of transition dairy cows. J Anim Sci. 93:18961904.

Lin, X.; Li, S.; Zou, Y.; Zhao, F.; Liu, J.; Liu, H. (2018): Lysine Stimulates Protein Synthesis by Promoting the Expression of ATB0,+ and Activating the mTOR Pathway in Bovine Mammary Epithelial Cells. J Nutr. Sep 1; 148(9):1426-1433.

Liu, G.; Ma, Z.; Shan, A.; Wang, L.; Bi, Z. (2016): Effects of dietary rumen protected lysine on milk yield and composition in lactating cows fed diets containing doble- low rapeseed meal. International Journal of Dairy Technology. 69(3): 380-385.

Longo, N.; Frigeni, F.; Pasquali, M. (2016): Carnitine transport and fatty acid oxodation. 2016. Biochim Biophys Acta., 1863(10): 2422-2435.

Lucy, MC.; Butler, ST.; Garverick, HA.(2014): Endocrine and metabolic mechanisms linking postpartum glucose with early embryonic and foetal development in dairy cows. Animal: an international journal of animal bioscience. 8: 1:82-90.

Matthews, C.; Crispie, F.; Lewis, E.; Reid, M.; Toole, P.; Cotter, PD. (2019): The rumen microbiome: a crucial consideration when optimising milk and meat production and nitrogen utilisation efficiency. Gut Microbes. 10 (2): 115-132.

McDowell, LR. (1989): Choline. In: Vitamins in animal nutrition: comparative aspect to human nutrition, L.R. McDowell (Ed.), New York: Academic Press, Inc., pp. 347-364, ISBN 0-12- 438372-1

Mohsen, MK.; Gaafar, HMA.; Khalafalla, MM.; Shitta, AA.; Yousif, AM. (2011): Effect of rumen protected choline supplementation on digestibility, rumen activity and milk yield in lactating Friesian cows. Slovak J. Anim. Sci. 2011; 44(1):13-20.

Muccioli, G.; Di Carlo, R. (1989): SAdenosyl-L-methionine restores prolactin receptors in the aged rabbit brain. European Journal of Pharmacology. 166, 2, 18: 223-230.

Osorio, JS.; Ji, P.; Drackley, JK.; Luchini, D.; Loor, JJ. (2013): Supplemental Smartamine M or MetaSmart during the transition period benefits postpartal cow performance and blood neutrophil function. J. Dairy Sci. 96:6248-6263.

Panel, ZH.; Chen, GA.; Broderick, ND.; Luchini, BK.; Sloan, E.(2011): Effect of feeding different sources of rumenprotected methionine on milk production and $\mathrm{N}$-utilization in lactating dairy cows. Journal of Dairy Science. 94: 4: 1978-1988.

Pawar, SP.; Kewalramani, N.; Thakur, SS.; Kaur, J. (2015): Effect of dietary rumen protected choline supplementation on milk choline content in crossbred cows. Indian J. Anim. Nutr. 32(1): 30-35. 
Peñagaricano, F.; Souza, AH.; Carvalho, PD.; Driver, AM.; Gambra, R.; Kropp, J.; Hackbart, KS.; Luchini, D.; Shaver, RD.; Wiltbank, MC.; Khatib, H.(2013): Effect of maternal methionine supplementation on the transcriptome of bovine preimplantation embryos. PLoS ONE. 8(8):e72302.

Pinotti, L.; Campagnoli, A.; Dell'Orto, V.; Baldi A. (2005). Choline: Is there a need in the lactating dairy cow? Livestock Production Science 98: 149 $-152$.

Ratika, K.; James Singh, RK.; Dahiya, SS.(2018): Methionine, Lysine and Choline in Dairy Cows: a Review Article. Int.J.Curr. Microbiol. App.Sci. 7: 3921-3934.

Rebouche, CJ. (2014): Carnitine. In: Ross AC, Caballero B, Cousins RJ, Tucker KL, Ziegler TR, eds. Modern Nutrition in Health and Disease. 11th ed. Baltimore: 440-446.

Sai, S.; Thakur, SS.; Kewalramani, N.; Chaurasia, M. (2014): Effect of Supplementation of Rumen Protected Methionine plus Lysine on Growth Performance, Nutrient Utilization and Blood Metabolites in Calves. Indian Journal of Animal Nutrition. 31: 1-7.

Sánchez, S.; Sánchez, CL.; Paredes, SD.; Rodriguez, AB.; Barriga, C. (2008): The effect of tryptophan administration on the circadian rhythms of melatonin in plasma and the pineal gland of rats. J. Appl. Biomed. 6: 177-186.

Sandberg, BN.; Hunt, CW.; Doumit, ME.; Richard, R.; Murdoch, GK. (2017): Effects of rumen protected-histidine supplementation dose on finishing beef cattle.Journal of Animal Science. 95.4:177.

Sathiyabarathi, M.; Arokia Robert, M.; Tamilmani, T. (2016): Rumenprotected choline: A significance effect on dairy cattle nutrition. Vet World. 9(8): 837-841.
Slominski, A.; Semak, I.; Pisarchik, A.; Sweatman, T.; Szczesniewski, A.; Wortsman, J. (2002): Conversion of Ltryptophan to serotonin and melatonin in human melanoma cells. FEBS Letters. 511 (1-3): 102-6.

Sugeng, MW.; Adriani, M.; Wirjatmadi, B.(2015): The Effect of Zinc and Lysine Supplementation on Infection Rate and CD4 Count In Elderly. Biochem Physiol.

Sun, F.; Cao, Y.; Cai, C.; Li, S.; Yu, C.; Yao, $Y$. (2016): Regulation of nutritional metabolism in transition dairy cows: energy homeostasis and health in response to post-ruminal choline and methionine. PLoS ONE. 11:160-659.

Tedeschi, LO.; Fox, DG.; Fonseca, MA.; Cavalcanti, MFL.(2015): Models of protein and AA requirements for cattle. R. Bras. Zootec. 44 .3.

Tetsuo, T.; Inoue, K.; Nishiki, H.; Sakata, M.; Seki, M.; Koga, T.; Ookubo, Y.; Akutsu, K.; Sato, S.; Saitou, K.; Shinohara, H.; Kuraisi, T.; Kajikawa, H.; Kurihara, M.(2019): Effects of rumen-protected methionine on milk production in early lactation dairy cattle fed with a diet containing $14.5 \%$ crude protein. Anim Sci J. 90:62-70.

Toledo, MZ.; Baez, GM.; Garcia-Guerra, A.; Lobos, NE.; Guenther, JN.; Trevisol, E.; Luchini, D.; Shaver, RD.; Wiltbank, MC. (2017): Effect of feeding rumen-protected methionine on productive and reproductive performance of dairy cows. PLOS ONE.

Vuvor, F.; Mohammed, H.; Ndanu, T.; Harrison, O. (2017): Effect of lysine supplementation on hypertensive men and women in selected peri-urban community in Ghana. BMC 3, 67.

Wang, F.; Shi, H.; Wang, S.; Wang, Y.; Cao, Z.; Li, S.(2019). Amino Acid Metabolism in Dairy Cows and their Regulation in Milk Synthesis. Current Drug Metabolism.20.1.

Weekes, TL.; Luimes, PH.; Cant, JP. (2006): Responses to AA Imbalances and 
Deficiencies in Lactating Dairy Cows. Journal of Dairy Science. 89, Issue 6:2177-2187.

Wessler, I.; Kirkpatrick, CJ. (2008): Acetylcholine beyond neurons: the non-neuronal cholinergic system in humans. Br J Pharmacol. 154:155871.

$W u, \quad$ G. (2014): Dietary requirements of synthesizable AAs by animals: a paradigm shift in protein nutrition. $\mathrm{J}$. Anim. Sci. Biotechnol. 5(1): 34.

Yin, J.; Li, T.; Yin, Y. (2016): Methionine and Antioxidant Potential. Journal of Antioxidant Activity. 1:2.
Zang, Y.; Silva, L.; helichkhan, M.; Miura, M.; Whitehouse, NL.; Chizzotti, ML.; Brito, AF.(2019): Incremental amounts of rumen-protected histidine increase plasma and muscle histidine concentrations and milk protein yield in dairy cows fed a metabolizable protein-deficient diet. J. Dairy Sci. 102:1-17.

Zom, RLG.; Baal, JV.; Goselink, RMA.; Bakker, JA.; Veth, MJ.; Vuuren, AM. (2011): Effect of rumen protected choline on performance, blood metabolites, and hepatic triacylglycerols of periparturient dairy cattle. J. Dairy Sci. 94: 4016-4027.

\title{
دور الاحماض الامينية المحمية في فسلجة المجترات: مراجعة<smiles>[14CH][14CH]=[14CH]</smiles>

E-mail: hemyatem@yahoo.com Assiut University web-site: www.aun.edu.eg

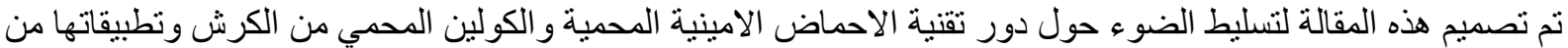

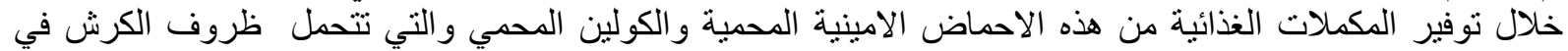

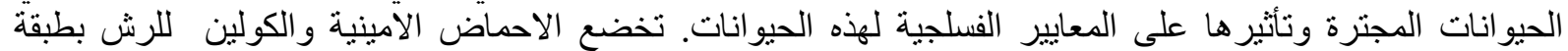

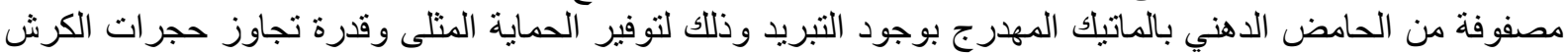

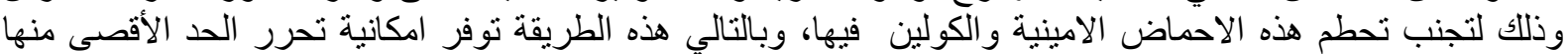

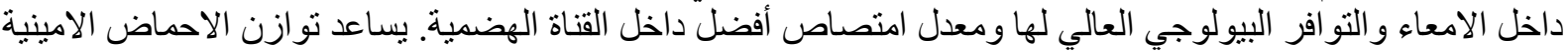

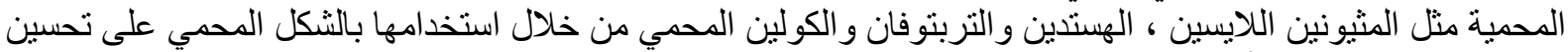

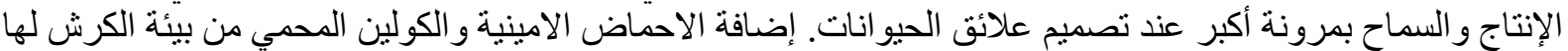

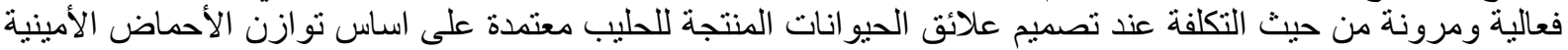

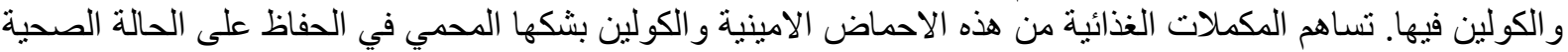

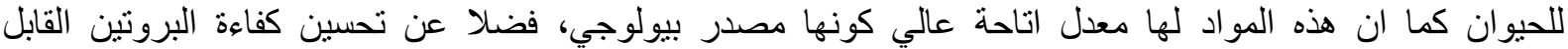

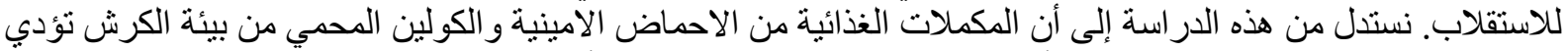

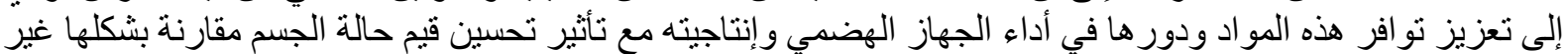

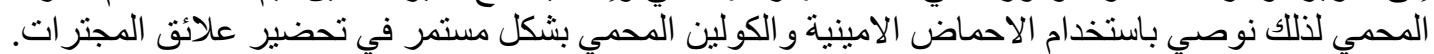

الكلمات المفتاحية: المثيونين المحمي ، اللايسين المحمي ، التربتوفان المحمي ، الكولين المحمي، المجترات
\end{abstract}

